\title{
WŁAŚCIWOŚCI FIZYKOCHEMICZNE POWIERZCHNI WYBRANYCH MATERIAŁÓW PO OBRÓBCE STRUMIENIOWO-ŚCIERNEJ
}

\begin{abstract}
Celem prezentowanych wyników badań jest ocena stanu warstwy powierzchniowej stali oraz metali lekkich w kontekście parametrów obróbki strumieniowej. Referat zawiera wyniki pomiarów, takich jak: odporność na korozję, chropowatość i mikrotwardość. Praca przez analizę materiałów prowadzi do oceny właściwości użytkowych wyrobów produkowanych z blach.
\end{abstract}

Słowa kluczowe: obróbka strumieniowo-ścierna, kształtowanie powierzchni izotropowych, odporność korozyjna

\section{Wprowadzenie}

Blacha jest typowym wyrobem hutniczym stosowanym w różnych gałęziach przemysłu. Realizowany przez autorów cykl badań dotyczy obróbki powierzchniowej blach. Obróbka warstwy powierzchniowej modyfikuje w materiałach istotne parametry: strukturę stereoskopową powierzchni oraz właściwości fizykochemiczne, takie jak: twardość, adhezja, chropowatość, aktywność chemiczna, przewodność ciepła i elektryczność $[1,3,5]$. Spośród wielu efektów obróbki strumieniowo-ściernej mało poznanym zagadnieniem jest odporność korozyjna materiału po obróbce $[4,6]$. W tym celu poczyniono przedstawione w pracy próby pomiaru odporności korozyjnej.

\section{Materiały poddane badaniom}

Badania realizowano na próbkach o wymiarach 60x20x2 mm. Stosowano kilkanaście typów materiałów, z których w niniejszej pracy ukazano dwa typowe:

\footnotetext{
1 Autor do korespondencji/corresponding author: Stanisław Zaborski, Politechnika Wrocławska, ul. I. Łukasiewicza 5, 50-370 Wrocław, tel.: 713202075, e-mail: stanisław.zaborski@pwr.wroc.pl

2 Tomasz Stechnij, Politechnika Wrocławska, e-mail: tomasz.stechnij@pwr.wroc.pl

3 Jan Masalski, Politechnika Wrocławska, e-mail: jan.masalski@pwr.wroc.pl

${ }^{4}$ Dariusz Poroś, Politechnika Wrocławska, e-mail: dariusz.poros@pwr.wroc.pl
} 
stop aluminium 2017 (PA6) oraz stal niskowęglową S255 (tab. 1). W referacie zaprezentowano badania odporności na korozję sześciu próbek w stanie po polerowaniu (oznaczane w tekście i na rysunkach jako St3 oraz PA) oraz w dwóch stanach po obróbkach strumieniowych (oznaczone a, b - stop glinu oraz c, d stal). Zarówno przed, jak i po obróbce prowadzono systematyczne pomiary cech warstwy powierzchniowej $[2,3,9]$ : badania mikroskopowe struktury geometrycznej, pomiary mikrotwardości oraz pomiary odporności na korozję.

Tabela 1. Materiały przeznaczone do obróbki w stanie pierwotnym (polerowane mechanicznie)

Table 1. Materials to be treated in the original state (mechanically polished)

\begin{tabular}{|c|c|c|}
\hline Parametr / Materiał & AlCu4MgSi & $\mathrm{S} 255$ \\
\hline Mikrotwardość & $H V_{50} 71,7$ & $H V_{50} 136,7$ \\
\hline Chropowatość & - & - \\
\hline$R a$ & 0,1 & 0,11 \\
\hline$R z$ & 0,8 & 0,45 \\
\hline$R p$ & 0,1 & 0,17 \\
\hline$R t$ & 0,9 & 0,47 \\
\hline
\end{tabular}

\section{Metoda obróbki}

Obróbka strumieniowo-ścierna może być prowadzona na mokro, hydrościerna [3]. W takim przypadku, aby zabezpieczyć powierzchnię przed korozją w strumieniu wodnym, dodaje się odczynniki zabezpieczające powierzchnię przed korozją (inhibitory) [7]. Z kolei w przypadku obróbki strumieniowo-ściernej na sucho należy pamiętać, aby tuż po obróbce przedmiot obrabiany dokładnie oczyścić z wszelkich pozostałości procesu. Niedostatecznie oczyszczona powierzchnia, przykładowo pozostałości pyłów, może być przyczyną powstania zalążków korozji, tzw. ogniw korozyjnych [5]. Zastosowano obróbkę suchą strumieniowo-ścierną, kabinową. Sterowano wszystkimi dostępnymi parametrami, a zatem: ciśnieniem strugi, rozmiarami dysz, rodzajem ziarna, kątami natarcia strugi, ułożeniem i posuwem przedmiotu obrabianego [8, 9]. Publikacja, z racji objętości, zawiera wyselekcjonowane wyniki badań. Zaprezentowano najistotniejsze parametry oraz ich wpływ na stan powierzchni. Przedstawione wyniki dotyczą obróbki, w której podczas różnicowania kąta strugi oraz ciśnienia pozostałe parametry były bez zmian (w myśl empirycznej zasady ceteris paribus).

\section{Wyniki pomiarów}

Porównanie podstawowych parametrów chropowatości powierzchni, zmierzonych po eksperymentach zawiera tab. 2. Rysunek 1 ilustruje różnice struktury geometrycznej powierzchni wybranych próbek. Parametry chropowatości 
zaprezentowane w tab. 2 nie ukazują w pełni złożoności struktury geometrycznej powierzchni. Zapewne pełna analiza stereometryczna ukazałaby istotne różnice w powstałych strukturach. Oczywiście zachodzi wyraźna zmiana elementarnych parametrów chropowatości wraz ze wzrostem ciśnienia i zmianami kąta natarcia - mająca również związek z typem obrabianego materiału. Wszystkie powierzchnie wykazują struktury anizotropowe o pseudolosowej kierunkowości powierzchni, co jest wynikiem zastosowanej obróbki.

Tabela 2. Wyniki badań, wybrane właściwości materiałów po obróbkach

Table 2. Results of investigations, selected properties of materials after machining

\begin{tabular}{|c|c|c|c|c|c|c|c|c|c|c|}
\hline Materiał & Ciśnienie & \multicolumn{3}{|c|}{$R z$} & \multicolumn{3}{c|}{$R a$} & \multicolumn{3}{c|}{$H V_{50}$} \\
\hline \multicolumn{2}{|c|}{ Kąt strumienia $\rightarrow$} & $30^{\circ}$ & $60^{\circ}$ & $90^{\circ}$ & $30^{\circ}$ & $60^{\circ}$ & $90^{\circ}$ & $30^{\circ}$ & $60^{\circ}$ & $90^{\circ}$ \\
\hline \multirow{2}{*}{$\mathrm{St3}$} & $\mathrm{P} 1=0,7 \mathrm{MPa}$ & 10,99 & 6,29 & 3,09 & 1,39 & 0,66 & 0,34 & 142,5 & 151,7 & 162,6 \\
\cline { 2 - 11 } S255 & $\mathrm{P} 2=1,2 \mathrm{MPa}$ & 15,45 & 12,36 & 18,54 & 2,06 & 1,85 & 2,58 & 149,1 & 162,7 & 167,7 \\
\hline $\mathrm{PA} 6$ & $\mathrm{P} 1=0,7 \mathrm{MPa}$ & 1,41 & 0,81 & 1,01 & 0,15 & 0,06 & 0,08 & 93,7 & 97,5 & 199,5 \\
\cline { 2 - 10 } AlCu $4 \mathrm{MgSi}$ & $\mathrm{P} 2=1,2 \mathrm{MPa}$ & 1,52 & 1,01 & 1,72 & 0,16 & 0,08 & 0,18 & 213,8 & 215,8 & 223,7 \\
\hline
\end{tabular}

a)

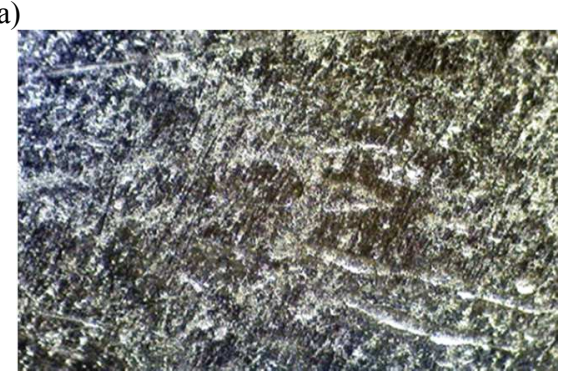

c)

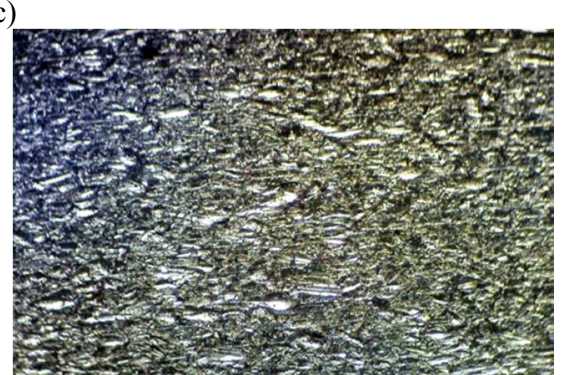

b)

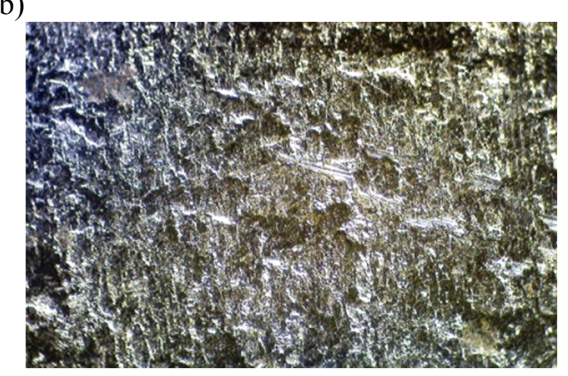

d)

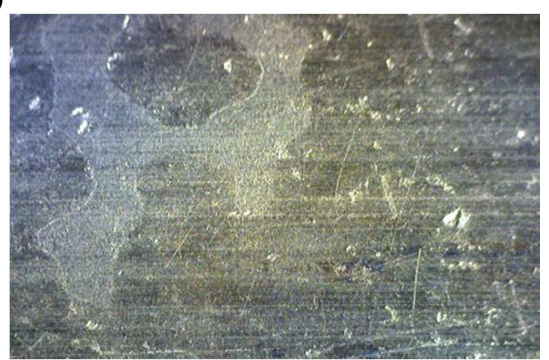

Rys. 1. Przykładowe porównanie powierzchni obrabianych blach, mikroskopia świetlna powiększenie $80 \mathrm{x}$ : a) stal po obróbce, ciśnienie $0,7 \mathrm{MPa}$, kąt strugi $60^{\circ}$, b) stal po obróbce, ciśnienie $0,7 \mathrm{MPa}$, kąt strugi $30^{\circ}$, c) stop glinu po obróbce strumieniowej, ciśnienie 1,2 MPa, kąt strugi $90^{\circ}$, d) stop glinu w stanie po polerowaniu

Fig. 1. Examplary comparison of surfaces of machined sheets, light microscopy - magnification 80x: a) steel after treatment, pressure $0.7 \mathrm{MPa}$, jet angle $60^{\circ}$, b) steel after treatment, pressure $0.7 \mathrm{MPa}$, jet angle $30^{\circ}, \mathrm{c}$ ) aluminium alloy, pressure $1.2 \mathrm{MPa}$, jet angle $90^{\circ}, \mathrm{d}$ ) aluminum alloy after polishing 
Badania podatności na korozję - polaryzacyjne wykonano na potencjostacie Schlumberger SI 1286, z wykorzystaniem oprogramowania do pomiarów CorrWare oraz do prezentacji i analizy wyników CorrView. Naczyńko elektrochemiczne było wyposażone w platynową elektrodę pomocniczą i kalomelową elektrodę odniesienia (z kapilarą Ługgina), a roztwór korozyjny zawierał: 8,6 chlorku sodu, 0,3 chlorku potasu i 0,243 chlorku wapnia ( $\left.\mathrm{w} \mathrm{g} / \mathrm{dm}^{3}\right)$ [7].

Aby ocenić odporność korozyjną, zmierzono zmiany potencjału korozyjnego (tzw. potencjału ogniwa otwartego) w czasie, wykonano pomiary oporu polaryzacyjnego (szybkość zmian potencjału wynosiła $0,167 \mathrm{mV} / \mathrm{s}$ ), zarejestrowano krzywe polaryzacyjne w zakresie potencjałów: od potencjału o $200 \mathrm{mV}$ niższego od potencjału ogniwa otwartego, do potencjału większego o $100 \mathrm{mV}$ względem nasyconej elektrody kalomelowej - NEK (szybkość zmian potencjału wynosiła $1 \mathrm{mV} / \mathrm{s}$ ). Wyniki badań przedstawiono na rys. 2-4. Potencjały korozyjne stali zmierzone bezpośrednio po zanurzeniu do roztworu są wyraźnie wyższe niż potencjały korozyjne stopu aluminium. Obróbka powierzchni nieznacznie podwyższa potencjały korozyjne stali i stopu aluminium. Opór $R_{p}$ stopu glinu jest kilkadziesiąt razy większy niż $R_{p}$ obrobionych powierzchniowo stali.

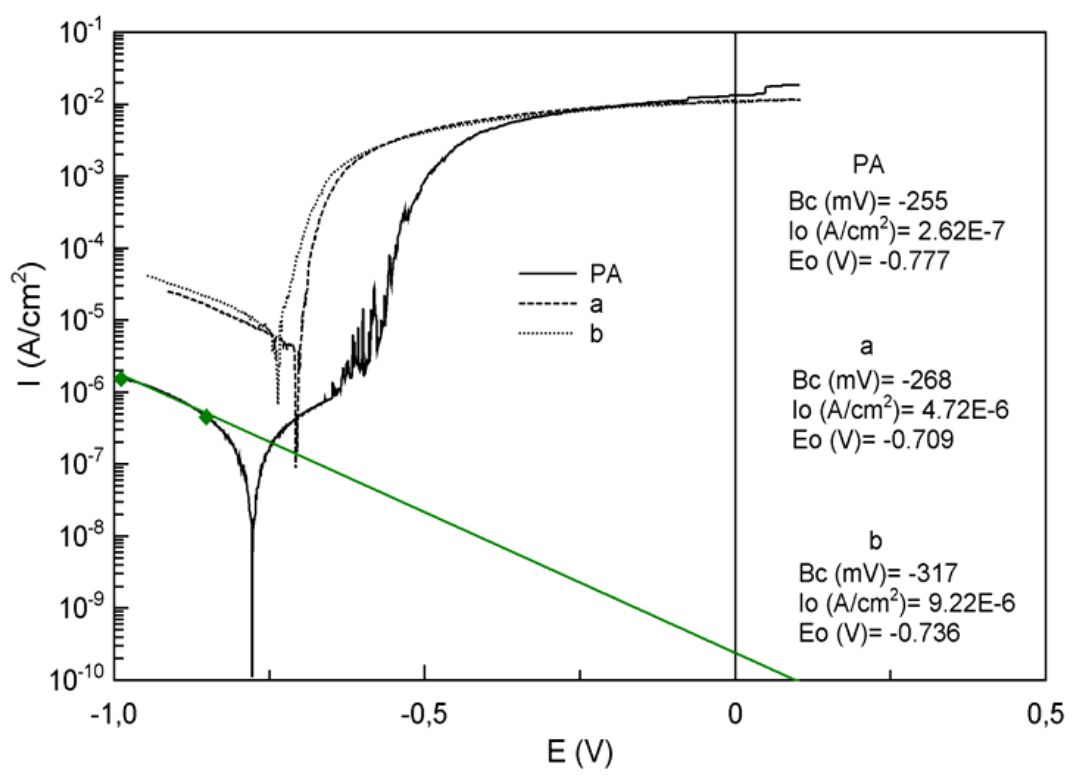

Rys. 2. Krzywa polaryzacyjna stopu aluminium

Fig. 2. Polarization curve of aluminum alloy 


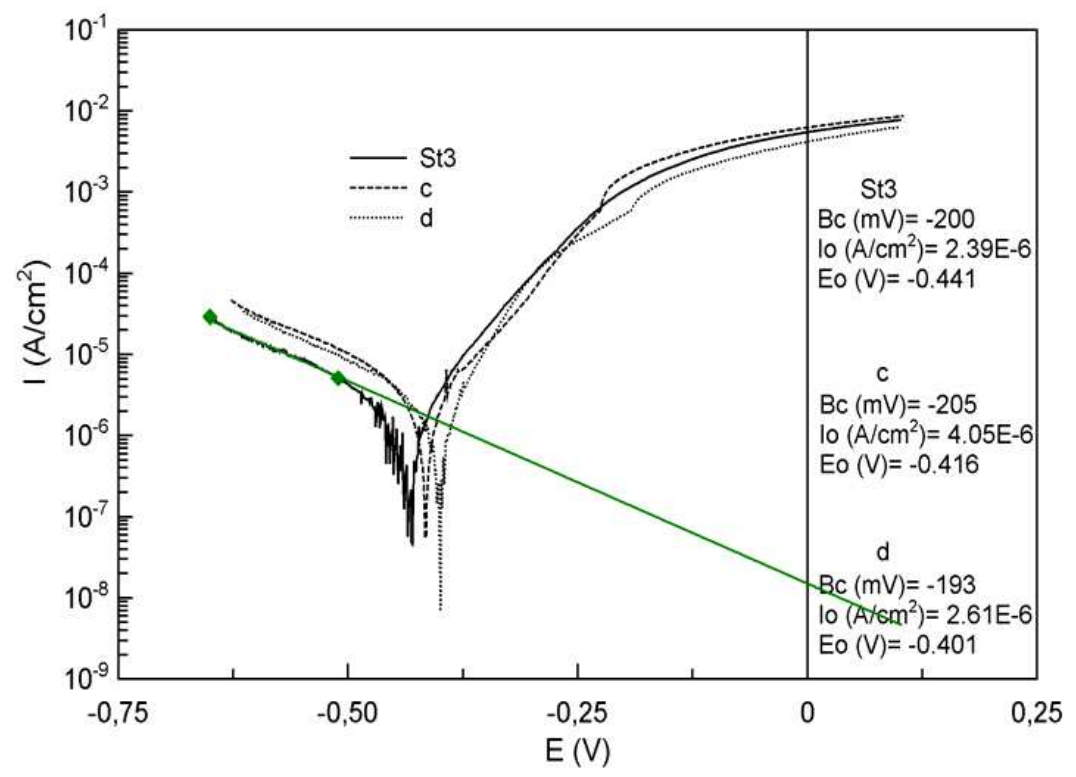

Rys. 3. Krzywa polaryzacyjna stali

Fig. 3. Steel polarization curve

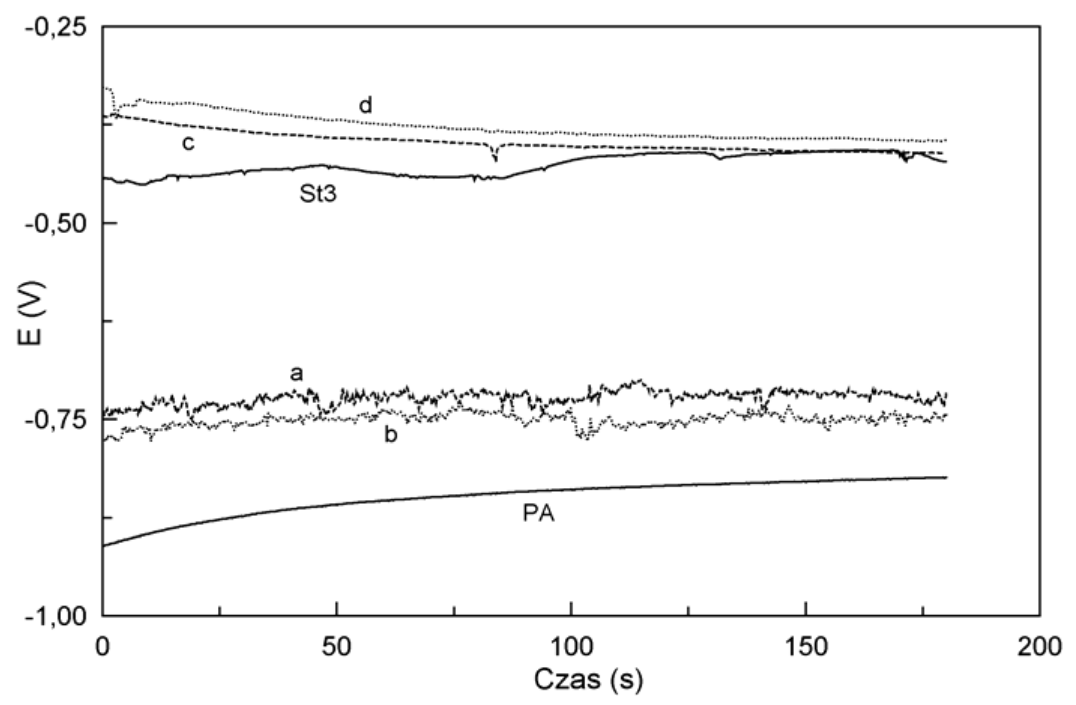

Rys. 4. Krzywe potencjałów dla stali i stopu aluminium

Fig. 4. The potential curves for steel and aluminium alloy 
Z analizy krzywych polaryzacyjnych wynika, że zarówno stal, jak i stop glinu nie ulegają pasywacji w roztworze korozyjnym. Szybkość korozji wyznaczono, opierając się na prostoliniowych (tafelowskich) katodowych odcinkach krzywych [5]. Obróbka powierzchniowa stopu glinu bardzo niekorzystnie wpływa na szybkość korozji tego stopu. Prąd korozji nieobrobionego stopu PA6 jest rzędu $2,6 \cdot 10^{-7} \mathrm{~A} / \mathrm{cm}^{2}$, a poddanego obróbce powierzchniowej odpowiednio: 4,7 $10^{-6}$ $\mathrm{A} / \mathrm{cm}^{2}$ i $9,2 \cdot 10^{-6} \mathrm{~A} / \mathrm{cm}^{2}$. Niekorzystny wpływ na odporność korozyjną wywiera również obróbka powierzchniowa stali. To pogorszenie odporności korozyjnej nie jest jednak tak wyraźne jak w przypadku stopu PA6. Gęstości prądów korozji są tego samego rzędu: od $2,4 \cdot 10^{-6}$ do $4,0 \cdot 10^{-6} \mathrm{~A} / \mathrm{cm}^{2}$.

\section{Podsumowanie}

Przedstawione badania prowadzą do konkluzji, że złożoność zjawisk zachodzących na powierzchni ciał stałych nie pozwala na formułowanie nieskomplikowanych i jednoznacznych technologicznych zaleceń. Wiele zjawisk stanowi o tym, że dla każdego materiału i konkretnego celu technicznego powierzchnie blach należy przygotowywać indywidualnie, dobierając parametry obróbkowe. Referat prezentuje nieliczne dane $\mathrm{z}$ wielu wykonanych prób i badań. W toku całego cyklu badawczego nie stwierdzono systematycznych czy modelowych zmian, wręcz przeciwnie - niekiedy niewielka modyfikacja powodowała istotne zmiany wybranych parametrów powierzchni. Ukazano także odwrotną zależność, przy typowych stalach niestopowych ferrytyczno-perlitycznych znaczne zmiany parametrów obróbki strumieniowo-ściernej nie powodowały istotnych różnic we właściwościach chemicznych powierzchni.

\section{Literatura}

[1] Borkowski J.: Fizykalne podstawy obróbki strumieniowo-ściernej, Studia i Materiały nr 6, Prace Naukowe ITBM Politechniki Wrocławskiej, Wrocław 1975.

[2] Borkowski P.: Teoretyczny model powierzchniowej obróbki wysokoenergetyczną strugą hydrościerną, XXIV Szkoła Naukowa Obróbki Ściernej, Kraków 2001.

[3] Kaczmarek J., Sikora J., Czyżewicz C.: Obróbka strumieniowo-ścierna, WNT, Warszawa 1963.

[4] Klimas T.: Proces śrutowania, Przegląd Mechaniczny, 13 (1984) 32-37.

[5] Poradnik galwanotechnika, Praca zbiorowa, WNT, Warszawa 1973.

[6] Woźniak K.: Materiały ścierne, WNT, Warszawa 1975.

[7] Wranglen G.: Podstawy korozji i ochrony metali, WNT, Warszawa 1975.

[8] Zaborski S., Pszczołowski W.: Zastosowanie mikrokulek szklanych w obróbce strumieniowo-ściernej, XXVI Szkoła Naukowa Obróbki Ściernej, Łódź 2003.

[9] Zaborski S., Stechnij T., Poroś D.: Wpływ obróbki strumieniowo-ściernej na strukturę geometryczną powierzchni wybranych metali nieżelaznych, Mechanik, 89 (2016) 1080-1081. 


\section{PHYSICOCHEMICAL PROPERTIES OF SURFACE OF SELECTED} MATERIALS AFTER ABRASIVE BLASTING

\section{S u m mary}

The aim of presented results of the investigations is the assessment of the state of the surface layer of steels and light metals in the context of the parameters of the blasting. This article contains the results of measurements of resistance to corrosion, roughness and microhardness. This work, through material analysis, leads to the assessment of the performance of sheet metal products.

Keywords: abrasive blasting, the formation of an isotropic surfaces, resistance to corrosion

DOI: $10.7862 / \mathrm{rm} .2017 .52$

Przestano do redakcji: 22.08 .2017

Przyjęto do druku: 18.10.2017 
